\title{
Influence of the ITZ Thickness on the Damage Performance of Recycled Concrete
}

\author{
Fuwei Xu $\mathbb{D}^{1,2}$ Bin Tian, ${ }^{1}$ and Gang $X u^{1}$ \\ ${ }^{1}$ College of Hydraulic and Environmental Engineering, China Three Gorges University, Yichang, Hubei 443002, China \\ ${ }^{2}$ College of Civil Engineering and Architecture, Hubei University of Arts and Science, Xiangyang, Hubei 441053, China \\ Correspondence should be addressed to Fuwei Xu; 445757999@qq.com
}

Received 19 November 2020; Revised 2 February 2021; Accepted 14 March 2021; Published 25 March 2021

Academic Editor: Peng Zhang

Copyright (c) 2021 Fuwei Xu et al. This is an open access article distributed under the Creative Commons Attribution License, which permits unrestricted use, distribution, and reproduction in any medium, provided the original work is properly cited.

The interfacial transition zone (ITZ) is a weak region of recycled concrete. To further study the influence of the ITZ on the damage performance of recycled concrete, a formula for calculating the ITZ thickness is derived, and the ITZ thickness is calculated for various recycled concrete mixtures with a recycled aggregate content of $30 \%$. The concrete model test method and finite element analysis software were used to numerically simulate common concrete and recycled concrete with ITZ thicknesses of $0.05 \mathrm{~mm}$, $1 \mathrm{~mm}, 2 \mathrm{~mm}, 3 \mathrm{~mm}$, and $4 \mathrm{~mm}$. The results show that the thickness of the ITZ has an obvious influence on the cracking strength of recycled concrete and that the cracking strength of recycled concrete decreases with increasing ITZ thickness. The cracks in recycled concrete initiate from the ITZ, and the damage degree increases with increasing ITZ thickness. Compared with that of common concrete, the cracking strength of recycled concrete with an ITZ thickness of no more than 2 mm (i.e., the replacement rate of the recycled aggregates is no more than 30\%) is not significantly reduced.

\section{Introduction}

Similar to ordinary concrete, recycled concrete is a kind of heterogeneous composite material, containing solid, liquid, and three-phase gas materials, made of recycled aggregates mixed with a certain proportion of natural aggregates, cement, water, and a certain proportion of additives for curing and hardening. However, unlike natural aggregates, recycled aggregates, which contain a large number of microcracks from mechanically damaged concrete, have old mortar attached to their surfaces. This is one of the main factors leading to the high porosity, strong water absorption, and relatively low density of recycled aggregates. At the microlevel, recycled concrete components include natural aggregates, an interfacial transition zone (ITZ) between the old mortar and natural aggregates, an ITZ between the new mortar and old mortar on the surface of the native aggregates and at the cross section between the transition layer (hereinafter referred to as the old interface layer) and old mortar, an ITZ between the new mortar and natural aggregates (hereinafter referred to as the new ITZ), and the new mortar matrix. In this paper, the old interface layer, the old mortar, and the new ITZ (i.e., the transition between the surface of the natural coarse aggregates and the new mortar matrix), collectively known as the regeneration region, is the primary ITZ between the coarse aggregates. The new mortar is called the common ITZ, as shown in Figure 1.

The ordinary concrete ITZ refers to the transition area between the aggregate and mortar matrix. Xie [1] studied the ITZ of concrete in 1983, and he divided the ITZ from the aggregates to the mortar into the following four microstructural models: the permeation and diffusion layer, contact layer, enrichment layer, and weak effect layer. According to Berger's sidewall effect [2], the water-cement ratio of the water film layer near the aggregate surface is higher than that of the cement slurry, and ettringite and other crystalline compounds with large crystals easily form around the aggregates, resulting in a loose structure and high porosity of the ITZ. The loose structure and high porosity reduce the bonding strength and permeability resistance of the interfacial zone, so the ITZ is referred to as the weak link in concrete. Professor $\mathrm{Wu}$ [3] studied the microstructure of 


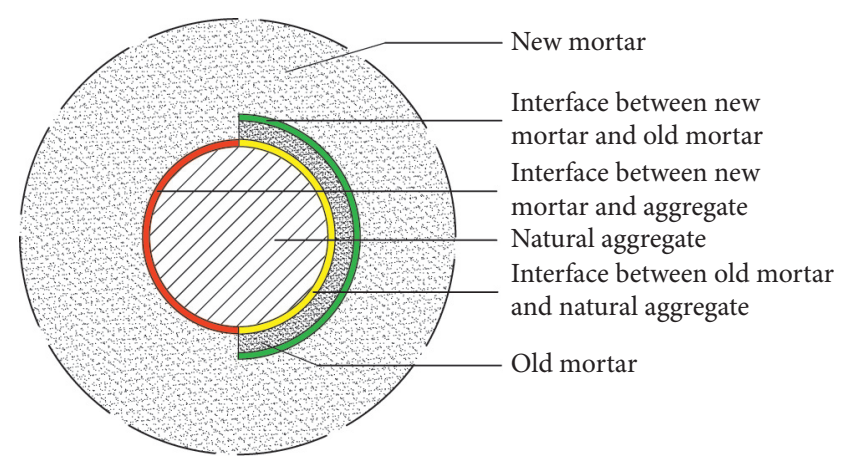

FIGURE 1: Microstructure and scanning electron microscope (SEM) image of recycled concrete [1].

the ITZ of concrete and found that the contents of calcium hydroxide and ettringite are obvious and that larger crystals, growth orientation, a high water-cement ratio, and a large porosity are observed. In addition, the weak region in concrete is the fundamental problem associated with composite materials; therefore, the macromechanical properties of the composite material were studied.

The recycled concrete ITZ contains the regeneration region of the ITZ and the common ITZ. The regeneration region of the ITZ combines the old interface layer and two mortar layers, such that the two old interface layers and the mortar layer produce a complex ITZ structure with a loose degree, and the porosity is much higher than that of the common ITZ, as shown in Figure 2. Etxeberria et al. [4] studied the ITZ structure of recycled concrete and found that the bond strength of the common ITZ was higher than that of the new interface layer and that the old interface layer was the weakest interface among the three. Dhir et al. [5] found that there was a large number of $\mathrm{CH}$ crystals in the new interface transition layer of the recycled concrete ITZ and that the crystal arrangement was obvious, which was also the weakest point in the recycled concrete. Tam et al. [6] carried out a model test containing 9 cylindrical recycled aggregate samples, and the model test methods were similar to those of Buyukozturk et al. [7] and Liu et al. [8]. The porosity of the old interface layer was higher than that of the old mortar and that of the new mortar was higher than that of the old mortar. Cracks appeared and developed mainly along the new surface layer of the recycled concrete with a large water-cement ratio (0.67), while cracks appeared and developed mainly along the old ITZ of the recycled concrete with a small water-cement ratio (0.40).

The ITZ (especially the recycled ITZ) is the area where cracks occur and develop and is the weakest region in recycled concrete. Many studies of the structure and cracking mechanism of the ITZ of recycled concrete have been carried out at home and abroad, but there are few reports on the quantitative analysis of the ITZ and the influence of its thickness on the performance of recycled concrete, so further research is needed. In this paper, the thickness and volume of the ITZ of recycled concrete are quantitatively analysed, and the variation in the thickness of the ITZ is numerically analysed for recycled concrete, which provides a reference for research on recycled concrete.

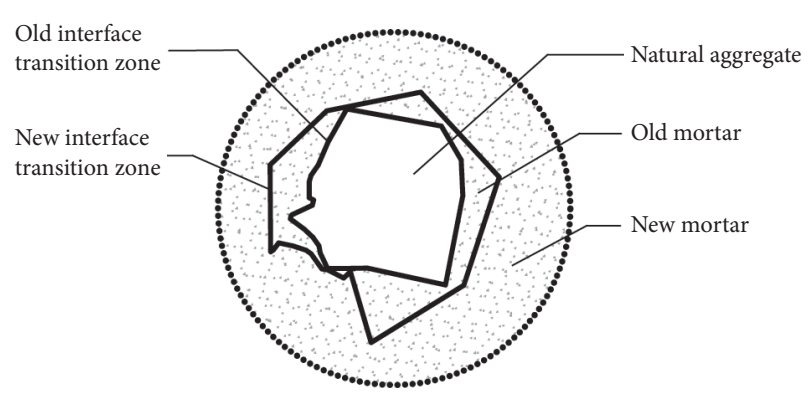

FIgURE 2: Schematic diagram of the interface transition zone of the recycled aggregates.

\section{Quantitative Analysis of the ITZ of Recycled Concrete}

The ITZ of recycled concrete includes the recycled ITZ and common ITZ. The common ITZ is the same as the ITZ in common concrete, which can be determined by referring to the research results for the common concrete ITZ [9]. Therefore, it is necessary to quantitatively analyse the recycled ITZ.

2.1. Quantitative Analysis of the ITZ Thickness. The regeneration ITZ from the natural aggregate surface inside the recycled aggregates to the edge of the new mortar includes the old interface layer, the old mortar, and the surface layer of the new materials. Recycled aggregates are mechanically obtained from waste concrete, and a large amount of old mortar is attached to the surface of the recycled aggregates produced from waste concrete. The old mortar layer is externally attached to the recycled aggregates and consists of the old interface layer and the old mortar layer. To quantitatively analyse the thickness of the recycled ITZ, the thickness of the old mortar externally attached to the recycled aggregates should be calculated first. The thickness of the recycled ITZ can be calculated based on the thickness of the old mortar and the surface layer of the new materials. The old mortar directly affects the water absorption rate of the recycled aggregates. Therefore, the old mortar adhesion rate is simplified in the literature [10] to be a single factor function of the water absorption rate, as shown in the following equation:

$$
w_{\text {water }}=F\left(w_{\text {oldcem }}\right),
$$

where $w_{\text {water }}$ is the water absorption of the recycled aggregates and $w_{\text {oldcem }}$ is the adhesion rate of the old mortar of the recycled aggregates.

Considering that the mechanical damage of the recycled aggregates results in a relatively high measured water absorption rate, the correction coefficient $\lambda$ (generally 1.2 1.3) is introduced, and equation (1) is amended as

$$
w_{\text {water }}=\frac{F\left(w_{\text {oldcem }}\right)}{\lambda} .
$$

The experimental results in the literature [11] show that there is a good linear correlation between the adhesion rate 
of the recycled aggregate mortar and the water absorption rate, apparent density, and crushing index as well as the randomness and uncertainty of the value $\lambda$ in equation (2). The expression of equation (2) can be directly used to obtain the linear expression in

$$
w_{\text {water }}=a \cdot w_{\text {oldcem }}+b .
$$

According to relevant studies, when the maximum particle size of the recycled aggregates is $16 \mathrm{~mm}, a=0.177$ and $b=0.36$ [12]; when the maximum particle size of the recycled aggregates is $32 \mathrm{~mm}, a=0.0825$ and $b=1.2828$ [13].

According to equation (3), the mortar adhesion rate can be expressed by

$$
w_{\text {oldcem }}=\frac{w_{\text {water }}-b}{a} .
$$

The difference in the linear expansion coefficient of different materials at different temperatures can also be used to conduct calcination tests to separate the old mortar from the surface of the aggregates and determine the content of old mortar. Bruno et al. [14] studied the linear expansion rate of cement mortar, limestone, pebbles, and green schist at different temperatures, and the linear expansion rate of different materials varied with temperature. When the temperature was low $\left(\leq 120^{\circ} \mathrm{C}\right)$, the difference in the linear expansion rate between different components was small, and the maximum expansion rate was only $0.04 \%$; however, when the temperature rose to $800^{\circ} \mathrm{C}$, the linear expansion rate of green schist reached more than twice that of cement mortar in C40, and the linear expansion rate of commonly used pebbles was also nearly twice that of cement mortar in C40, with obvious differences. After high-temperature calcination, the aggregates were put into a high-speed ball mill for ball grinding. The mutual collision of the ball grinding beads could effectively separate the mortar and aggregates, and an accurate mortar content could be obtained. The mortar content is given by

$$
w_{\text {oldcem }}=\frac{\Delta G}{G_{\text {Rag }}} \times 100 \%=\frac{G_{\text {Rag }}-G_{\mathrm{ag}}}{G_{\text {Rag }}} \times 100 \%,
$$

where $G_{\text {Rag }}$ is the weight of the recycled aggregate sample after drying, $G_{\mathrm{ag}}$ is the weight of the recycled aggregate sample after high-temperature calcination, and $\Delta G=G_{\text {Rag }}-$ $G_{\text {ag }}$ is the mortar content in the reclaimed aggregates.

In addition, the volume of recycled aggregate mortar content can be expressed by

$$
V_{\text {oldcem }}=\frac{\Delta G}{\rho_{\text {cement }}}=\frac{G_{\text {Rag }} w_{\text {oldcem }}}{\rho_{\text {cement }}} \times 100 \% .
$$

According to equations (4) and (6), the relationship between the mortar content volume and water absorption can be expressed by

$$
V_{\text {oldcem }}=\frac{G_{\text {Rag }}\left(w_{\text {water }}-b\right)}{\rho_{\text {cement }} \cdot a} \times 100 \% .
$$

The volume of recycled aggregates after residue is removed from the process of sieving is as follows: $V_{\mathrm{ag}}=V_{\mathrm{Rag}}-V_{s}$. Relevant studies $[15,16]$ show that the volume percentage of the aggregates in concrete is basically the same as the area percentage of the aggregates in a certain section. Therefore, the area ratio between the old mortar and primary aggregates at a certain interface of the reclaimed aggregates can be calculated to obtain the thickness of the mortar attached to the reclaimed aggregates. Therefore, the area ratio $f_{A}$ between the old mortar and the natural aggregates in the recycled aggregates can be expressed by

$$
f_{A}=\frac{V_{\text {cement }}}{V_{\text {ag }}}=\frac{\rho_{\text {ag }} w_{\text {oldcem }}}{\rho_{\text {cement }}\left(1-w_{\text {oldcem }}\right)} .
$$

The thickness $\delta_{\text {ITZ }}^{\text {old }}$ of the old mortar attached to the outside of the recycled aggregates with particle size $d$ is obtained in

$$
\delta_{\text {ITZ }}^{\text {old }}=\frac{D-D \cdot \sqrt{1 /\left(1+f_{A}\right)}}{2} .
$$

The thickness of the mortar attached to the outside of the recycled aggregates as well as the thickness of the old interface layer and the old mortar is obtained. Therefore, the thickness $\delta_{\text {ITZ }}^{\text {RC }}$ of the regenerated ITZ is equal to the sum of the thickness $\delta_{\text {ITZ }}^{\text {old }}$ of the attached old mortar (including the old mortar and the old interface layer) and the thickness $\delta_{\text {ITZ }}^{\text {new }}$ of the surface layer of the new materials (which is also equal to that of the ordinary ITZ). $\delta_{\mathrm{ITZ}}^{\mathrm{RC}}$ can be expressed by

$$
\delta_{\mathrm{ITZ}}^{\mathrm{RC}}=\delta_{\mathrm{ITZ}}^{\mathrm{old}}+\delta_{\mathrm{ITZ}}^{\text {new }}
$$

2.2. Analysis of the Thickness of the ITZ. According to [16], the mortar contents of reclaimed concrete prepared with recycled coarse aggregates (labelled C20 C50) are shown in Table 1.

According to the first-order mixture of the recycled coarse aggregate particles with sizes of $5 \sim 25 \mathrm{~mm}$, the thickness of the ITZ corresponding to different particle sizes of recycled coarse aggregates is shown in Table 2 and Figure 3.

Table 2 and Figure 3 show that the strength of abandoned concrete has a significant influence on the mortar adhesion thickness on the surface of recycled aggregates, and the average mortar adhesion thickness on the surface increases with the increase in the particle size of the recycled aggregates.

In the literature [3], academician $\mathrm{Wu}$ pointed out that the thickness of the ITZ of ordinary concrete is generally $30 \sim 40 \mu \mathrm{m}$, and Prokopski and Halbiniak [9] found that the final thickness of the ITZ is not more than $100 \mu \mathrm{m}$ based on the quantitative calculation of the thickness of the ITZ of ordinary concrete. When the approximate thickness of the common ITZ is taken as $70 \mu \mathrm{m}$, the thickness of the regenerated ITZ corresponding to different aggregate particle sizes is shown in Table 3. 
TABLE 1: Mortar contents of reclaimed concrete with coarse aggregates.

\begin{tabular}{lc}
\hline Strength grade of abandoned concrete & Mortar content (\%) \\
\hline C20 & 44.8 \\
C30 & 40.4 \\
C40 & 33.4 \\
C50 & 26.4 \\
\hline
\end{tabular}

TABle 2: Average thickness of the adhesive mortar of the recycled coarse aggregates with different particle sizes and abandoned concrete strength $(\mathrm{mm})$.

\begin{tabular}{lccccc}
\hline $\begin{array}{l}\text { Strength grade of abandoned } \\
\text { concrete }\end{array}$ & 5 & 7.5 & 12 & 17.5 & 20 \\
\hline C20 & 0.42 & 0.63 & 1.01 & 1.47 & 1.68 \\
C30 & 0.39 & 0.58 & 0.93 & 1.36 & 1.56 \\
C40 & 0.33 & 0.5 & 0.81 & 1.17 & 1.34 \\
C50 & 0.27 & 0.41 & 0.676 & 0.96 & 1.10 \\
\hline
\end{tabular}

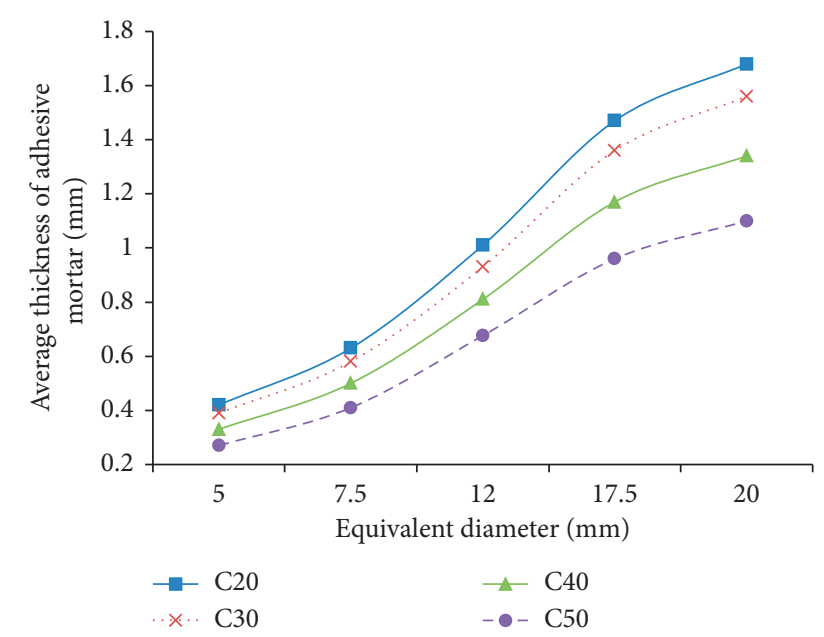

FIgURE 3: Average thickness of the mortar attached to the surface of the reclaimed aggregates with different particle sizes.

TABLE 3: Interfacial transition zone thickness corresponding to different particle sizes and abandoned concrete strengths in recycled concrete $(\mathrm{mm})$.

\begin{tabular}{lcccccc}
\hline \multicolumn{2}{l}{$\begin{array}{l}\text { Strength grade of } \\
\text { abandoned concrete }\end{array}$} & 5 & 7.5 & 12 & 17.5 & 20 \\
\hline \multirow{4}{*}{ Recycled ITZ } & C20 & 0.49 & 0.70 & 1.08 & 1.54 & 1.75 \\
& C30 & 0.46 & 0.65 & 1.00 & 1.43 & 1.63 \\
\multirow{2}{*}{ Normal ITZ } & C40 & 0.40 & 0.57 & 0.88 & 1.24 & 1.41 \\
\hline
\end{tabular}

\section{Influence of the ITZ Thickness on the Damage Performance of Recycled Concrete}

Model tests or numerical analyses based on model tests are commonly used to simplify the analysis of the mechanical properties of concrete. In 1966, Shah and Winter [17] proposed the concrete model test method for the first time and carried out a uniaxial compression test on a model containing 1 aggregate. The ITZ was the first area to experience damage. In 1971, Buyukozturk et al. [7] conducted uniaxial compression tests on a model containing 9 aggregates, and in 1972, Liu et al. [8] conducted uniaxial and biaxial compression tests on a model containing 9 aggregates and found that concrete cracks first appeared in the ITZ. In 2001, Lawler et al. [18] used digital image processing technology (DIC) to study concrete models containing 1, 5, and 13 aggregates. From the perspective of compression failure characteristics, the damage is also initiated in the ITZ. In 2020, Harish et al. [19] researched the tensile constitutive relation of recycled concrete aggregate performance and the influence of nine recycled concrete aggregates in uniaxial tensile modelling. The results showed that the damage in the recycled concrete began in the ITZ, that the tensile peak stress increased with the increase in recycled aggregates outside the thickness of the attached old mortar, and that the damage decreased in the elastic model. The above model tests show that the ITZ is the first to be damaged in either ordinary concrete or recycled concrete. However, the influence of the thickness of the ITZ on the mechanical properties of recycled concrete has not been completely clarified. In this paper, 9 recycled aggregates were used to carry out numerical simulation model tests of recycled concrete to study the influence of the ITZ on the mechanical properties of recycled concrete with different thicknesses.

3.1. Model Design and Material Property Determination. The numerical model of the recycled concrete has dimensions of $150 \mathrm{~mm} \times 150 \mathrm{~mm} \times 30 \mathrm{~mm}$, and the diameter of the recycled aggregates is $38 \mathrm{~mm}$ with a spacing of $9 \mathrm{~mm}$. The thicknesses of the ITZ (including the old ITZ, old mortar, and new ITZ) are $0.05 \mathrm{~mm}, 1 \mathrm{~mm}, 2 \mathrm{~mm}, 3 \mathrm{~mm}$, and $4 \mathrm{~mm}$, corresponding to models of ordinary concrete (NCA) and four kinds of recycled concrete (RC10, RC20, RC30, and RC40), as shown in Figure 4(a). The strength of the natural aggregates in the reclaimed aggregates is much larger than the strength of the ITZ and mortar. According to [20], the natural aggregates in the reclaimed aggregates are taken as the elastic material in the numerical simulation. The density is set to $2600 \mathrm{~kg} / \mathrm{m}^{3}$, the elastic modulus is $70 \mathrm{GPa}$, and $\mu$ is set to 0.16 . The density of the new mortar is set to $2200 \mathrm{~kg} /$ $\mathrm{m}^{3}$, the elastic modulus is $23 \mathrm{GPa}$, and $\mu$ is set to 0.2 . In the selection of the material properties of the ITZ, Lutz et al. [21] considered that the elastic modulus of the ITZ at 28 days was $30-50 \%$ of the mortar, so the elastic modulus of the ITZ was set to $12 \mathrm{GPa}$, and $\mu$ was 0.2 .

ABAQUS finite element analysis software is used for numerical analysis of the model. The numerical model is established by sweeping segmentation. The model mesh element is C3D8R, an 8-node linear hexahedral reduction integral element (Figure 4(b)). The new mortar and the ITZ adopt the plastic damage model of concrete without cracks, and the damage state of the model is judged by the compression damage. The new mortar in the model adopts the constitutive relation of the mortar stress-strain curve as in [22] (as shown in Figure 5). As presented in [21], the stress in 


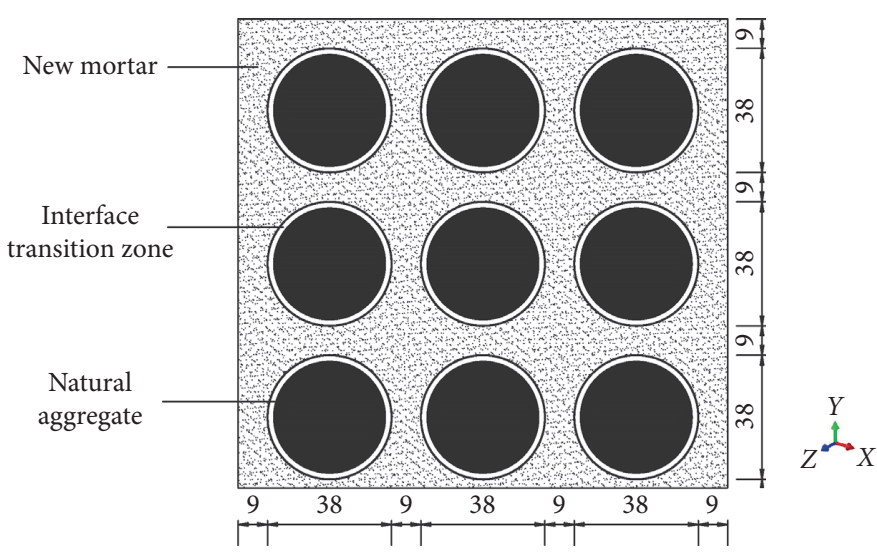

(a)

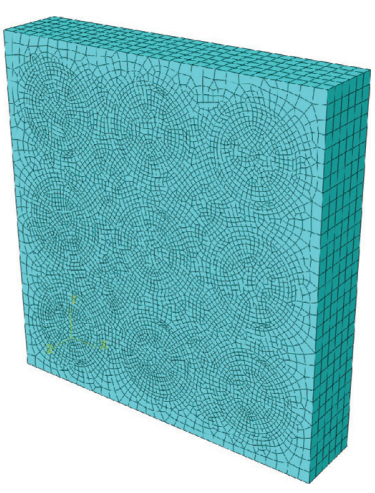

(b)

Figure 4: Schematic diagram of the (a) recycled concrete model and (b) finite element mesh.

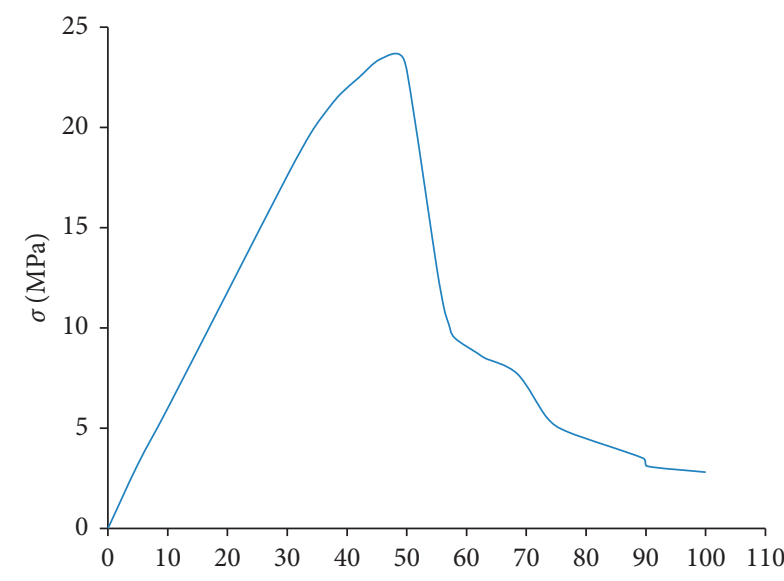

(a)

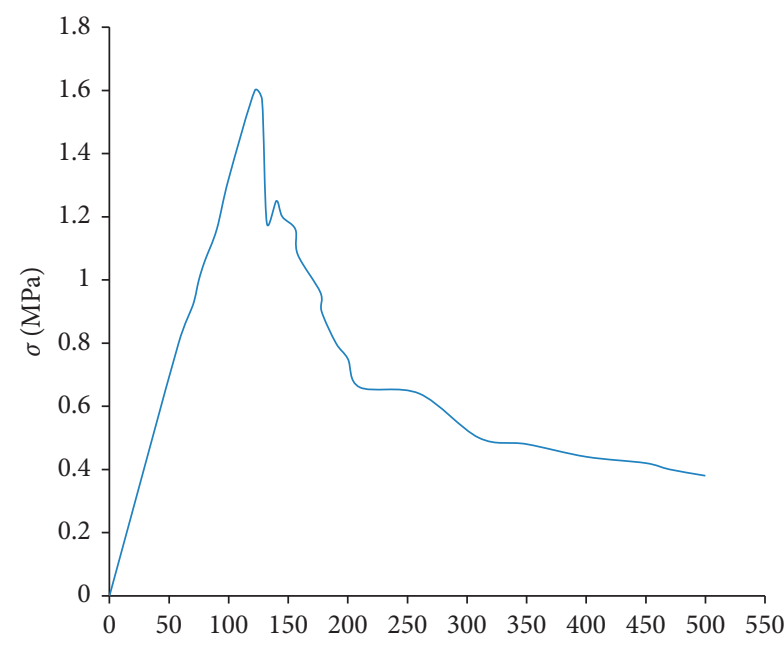

(b)

FIGURE 5: Stress-strain curve of new mortar. (a) Uniaxial compression stress-strain curve. (b) Uniaxial tensile stress-strain curve.

the ITZ is selected according to $50 \%$ of the new mortar, and the strain is taken as $100 \%$ of the strain in the new mortar. Stress control loading is adopted for the recycled concrete model, and surface loads are simultaneously applied at both ends. The initial load is $5 \mathrm{MPa}$, the maximum load is $40 \mathrm{MPa}$, the loading time is $10 \mathrm{~s}$, the maximum incremental steps are set to 5,000 steps, and the calculation stops if the increment exceeds $10 \mathrm{~s}$ or 5,000 steps.

\subsection{Numerical Simulation Results of the Recycled Concrete} Model. The results of the 5 models are analysed, and the thickness of the ITZ has an obvious influence on the damage of the concrete model during loading. With the increase in the thickness of the ITZ, the first damage location of the concrete model in the loading process is in the ITZ, and the damage area increases with the increase in the load. RC30 is the regenerated concrete model; for example, when the load reaches $4.022 \mathrm{~s}$, the ITZ of the $X$-direction stress reaches
$1.65 \mathrm{MPa}$, and cracks initiate in the ITZ; after $10 \mathrm{~s}$ of loading, the model of the ITZ and the tensile stress area of the new mortar expand continuously, the damage area expands continuously, and the mortar surrounding the ITZ exhibits a large area of damage, as shown in Figures 6 and 7. The concrete model with an ITZ thickness ranging from $0.05 \mathrm{~mm}$ to $4 \mathrm{~mm}$ shows that cracking begins to appear in the ITZ when loading becomes more severe with increasing thickness, as shown in Figure 8.

By comparing the damage evolution process of 5 different concrete models, the concrete models with different ITZ thicknesses start to crack at different times. The normal concrete model begins to crack at $7.128 \mathrm{~s}$, and the recycled concrete model of RC10 RC40 begins to crack from $6.525 \mathrm{~s}$ to $5.375 \mathrm{~s}$. In general, cracking initiates sooner in recycled concrete than ordinary concrete; the damage evolution in the ITZs with thicknesses of $1 \mathrm{~mm}$ and $2 \mathrm{~mm}$ is close to that in the ITZs with thicknesses of $3 \mathrm{~mm}$ and $4 \mathrm{~mm}$; and in the ITZs with thicknesses of $3 \mathrm{~mm}$ and $4 \mathrm{~mm}$, damage occurs 


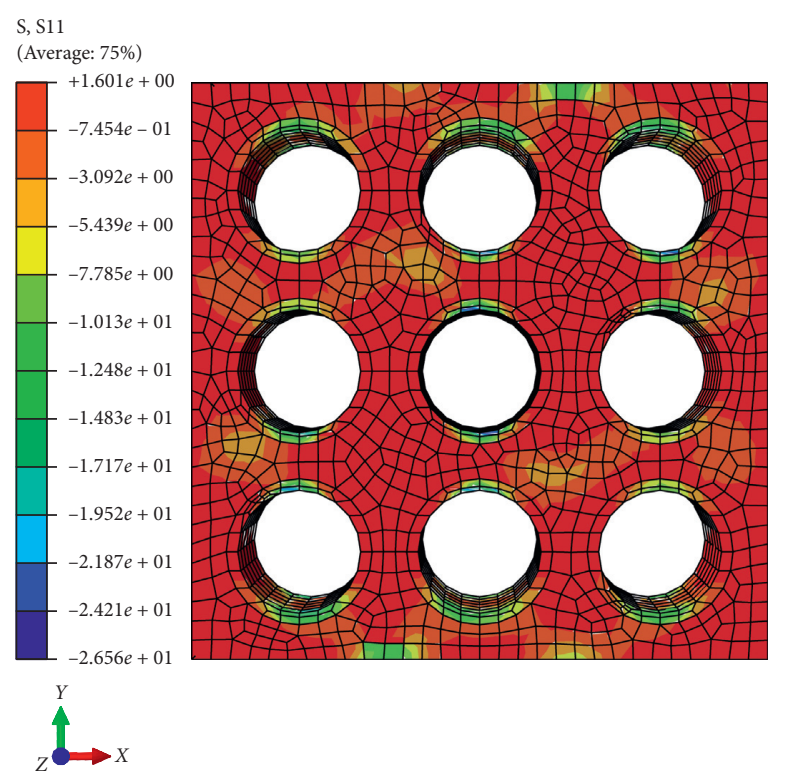

(a)

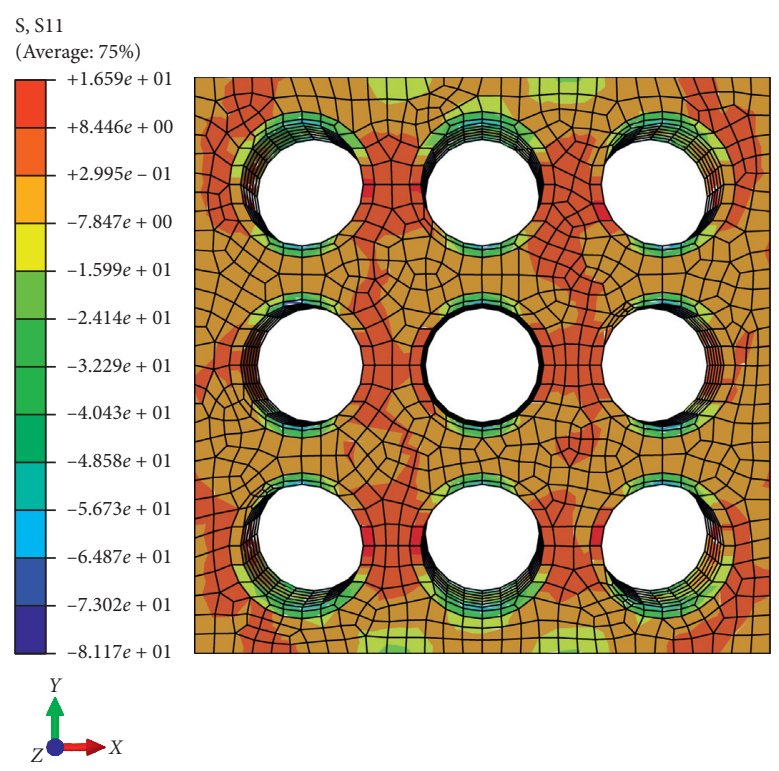

(b)

Figure 6: Stress in the $X$-direction of RC30 (unit: MPa). (a) $4 \mathrm{~s}$. (b) $10 \mathrm{~s}$.

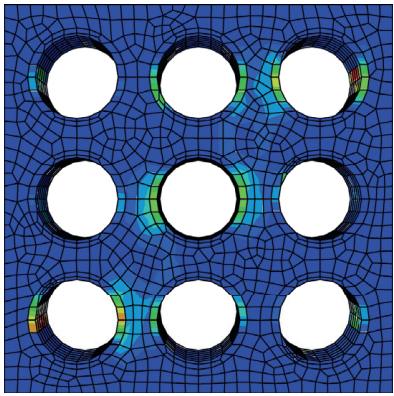

(a)

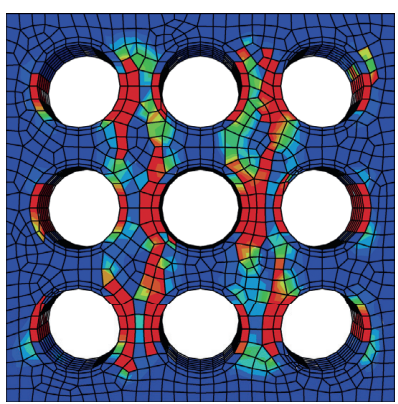

(e)

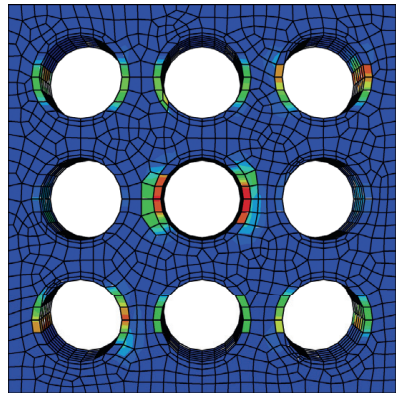

(b)

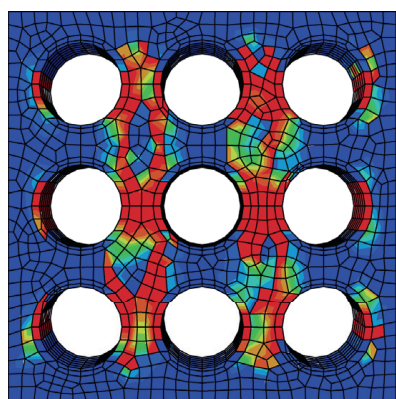

(f)

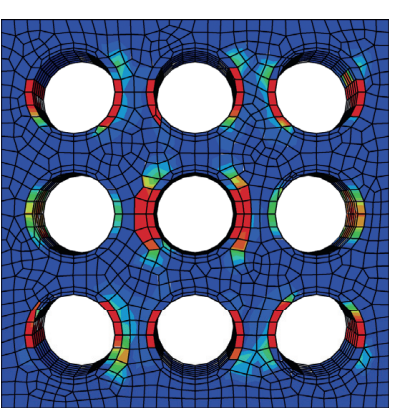

(c)

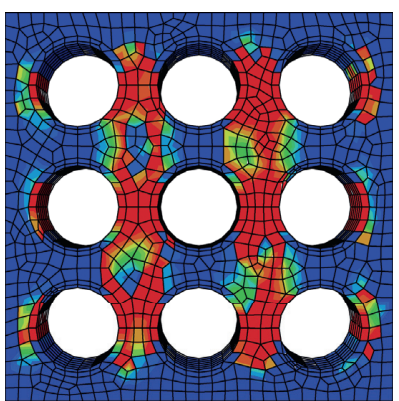

(g)

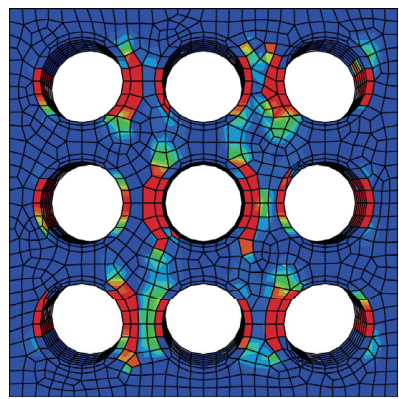

(d)

Figure 7: Damage evolution in the RC30 concrete model. (a) 4 s. (b) 5 s. (c) 6 s. (d) 7 s. (e) 8 s. (f) 9 s. (g) $10 \mathrm{~s}$.

earlier in recycled concrete than ordinary concrete, as shown in Figure 8.

When the thicknesses of the ITZs are $1 \mathrm{~mm}, 2 \mathrm{~mm}$, $3 \mathrm{~mm}$ and $4 \mathrm{~mm}$, the replacement rates of the recycled aggregates in the recycled concrete based on the volume ratio are approximately $20 \%, 30 \%, 50 \%$, and $80 \%$, respectively. When the model concrete cracks, the loads are 33 MPa, 31.6 MPa, 30.9 MPa, 27.75 $\mathrm{MPa}$, and 26.6 MPa.
Compared with the test results in [23-25], the results and the variation trend in the current study are consistent, as shown in Figures 9 and 10. Figures 9 and 10 show that compared with that of normal concrete, the cracking load of the recycled concrete decreases with increasing ITZ thickness, especially when the thickness of the ITZ is more than $2 \mathrm{~mm}$. The concrete cracking load of the model with a recycled aggregate replacement rate greater than $30 \%$ is 


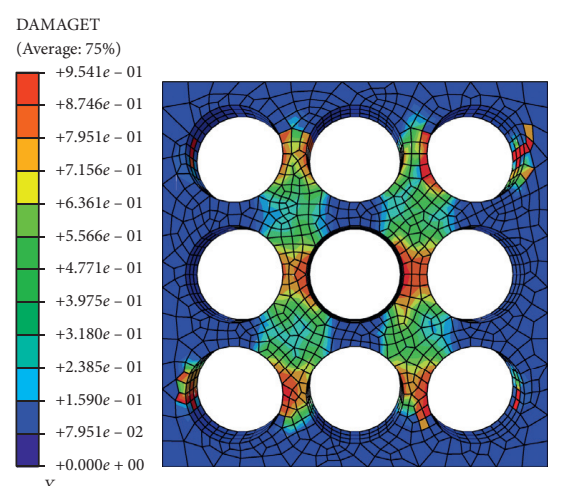

$\stackrel{Y}{\longrightarrow} \underset{Z}{\longrightarrow}$

(a)

DAMAGET

(Average: $75 \%$ )

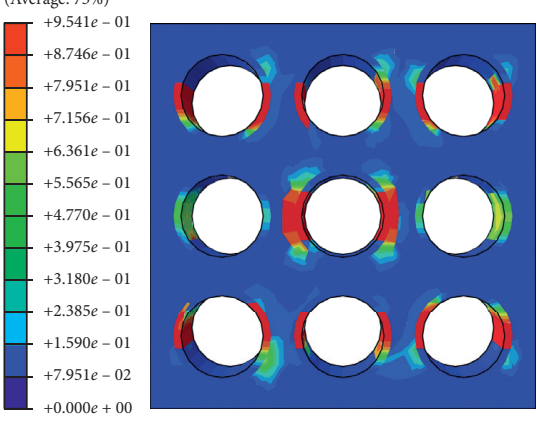

$\underset{Z}{\stackrel{Y}{\longrightarrow}}$

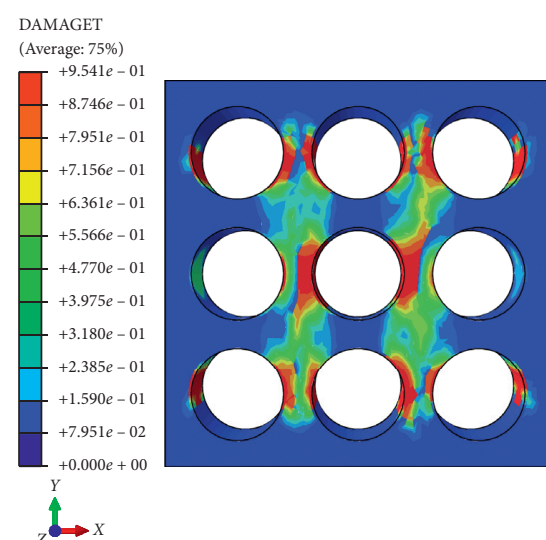

$\underset{Z}{\longrightarrow}$
DAMAGET (Average: $75 \%$ )

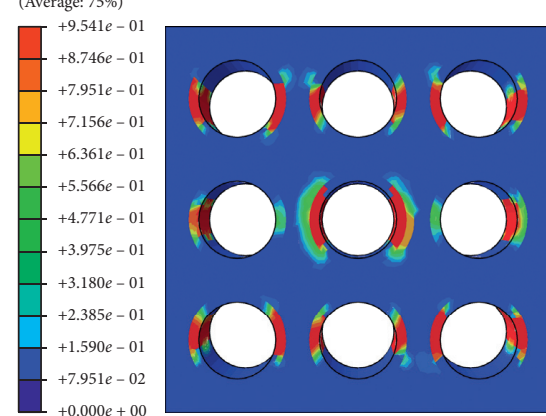

$\underset{Z}{\stackrel{Y}{\longrightarrow}}$
DAMAGET

(Average: $75 \%$ )

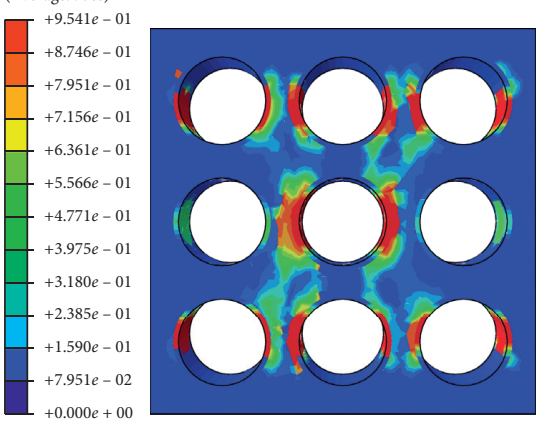

$\underset{Z}{\stackrel{Y}{\longrightarrow}}$ (b)

(c)

(e)

FIGURE 8: Initial damage diagram in the ITZ for 5 types of recycled concrete models. (a) NCA. (b) RC10. (c) RC20. (d) RC30. (e) RC40.

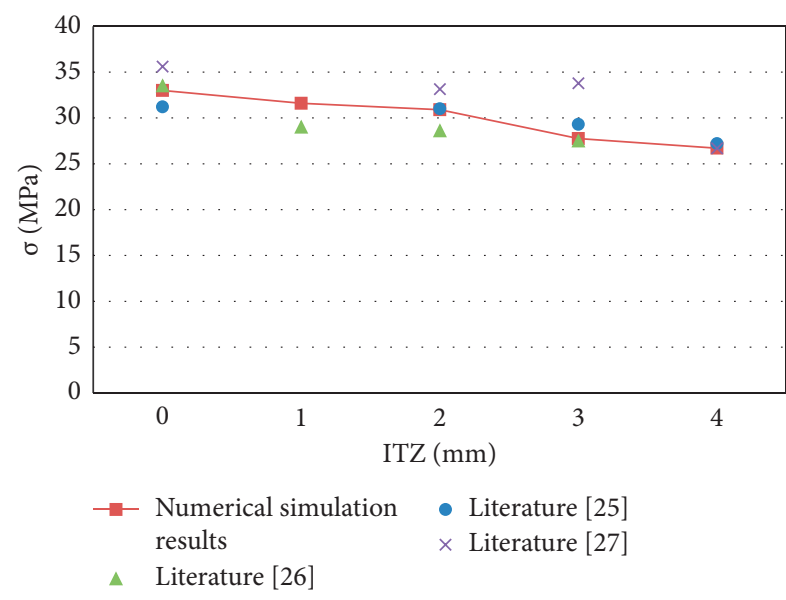

FIgURE 9: Cracking load in different concrete models.

significantly reduced, and the decrease in the concrete strength is not very obvious. When the thickness of the ITZ is more than $2 \mathrm{~mm}$, the thickness of the ITZ has a significant influence on the damage performance of recycled concrete, and the cracking strength of concrete is also significantly reduced.

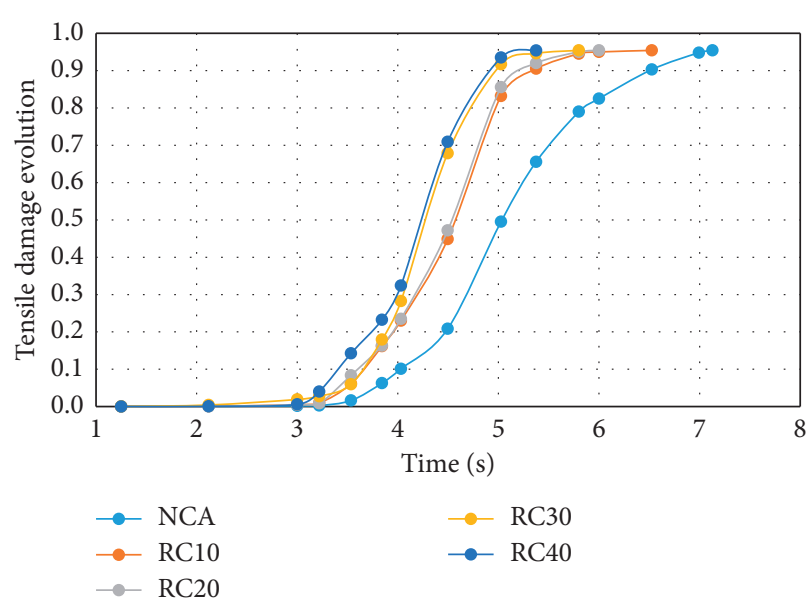

FIgURE 10: Damage evolution of concrete models with different ITZ thicknesses.

\section{Conclusion}

The following conclusions can be drawn based on the quantitative analysis of the ITZ thickness of recycled concrete and the numerical simulation of the cracking evolution of the concrete model: (1) the thickness of the old mortar 
attached to the recycled aggregates and the recycled ITZ thickness increase with the increase in the aggregate particle size and decrease with the increase in the strength of the abandoned concrete; (2) with the increase in the thickness of the ITZ, the cracking strength of the recycled concrete model decreases continuously, which is consistent with the variation law of the test results in the relevant literature; (3) the numerical simulation results of different concrete models show that the cracking of recycled concrete starts from the ITZ and that the damage degree increases with the increase in the thickness of the ITZ; and (4) when the thickness of the ITZ is no more than $2 \mathrm{~mm}$ (i.e., the replacement rate of recycled aggregates is not more than $30 \%$ ), the cracking strength of recycled concrete is not significantly reduced compared with that of ordinary concrete.

\section{Data Availability}

The data used to support the findings of this study are available from the corresponding authors upon request.

\section{Conflicts of Interest}

The authors declare that they have no conflicts of interest.

\section{Acknowledgments}

The authors are grateful to the Natural Science Foundation of China for supporting this paper via the Surface Performance Evolution of Concrete Face Rockfill Dam under the Action of Multi-Factor Coupling project (No. 51879145). The authors would also like to thank Professor Tian Bin, Professor Xu Gang, Dr. Chen Bofu, and Dr. Chen Lei for several useful discussions during the course of this research.

\section{References}

[1] S. Xie, "Study on interfacial bonding in cement-based composites," Journal of the Chinese Ceramic Society, vol. 11, no. 4, pp. 489-497, 1983.

[2] R. L. Berger, D. S. Cahn, and J. D. Mcgregor, "Calcium hydroxide as a binder in portland cement paste," Journal of the American Ceramic Society, vol. 53, no. 1, pp. 57-58, 2010.

[3] Z. Wu, "Interface problems of cement-based composites," Journal of Wuhan University of Technology, vol. 2, pp. 143-149, 1982.

[4] M. Etxeberria, E. Vázquez, and A. Marí, "Microstructure analysis of hardened recycled aggregate concrete," Magazine of Concrete Research, vol. 58, no. 10, pp. 683-690, 2006.

[5] R. K. Dhir, M. C. Limbachiya, and T. Leelawat, "Suitability of recycled concrete aggregate for use in BS 5328 designated mixes," Proceedings of the Institution of Civil Engineers-Structures and Buildings, vol. 134, no. 3, pp. 257-274, 1999.

[6] V. W. Y. Tam, X. F. Gao, and C. M. Tam, "Microstructural analysis of recycled aggregate concrete produced from two-stage mixing approach," Cement and Concrete Research, vol. 35, no. 6, pp. 1195-1203, 2005.

[7] O. Buyukozturk, A. H. Nilson, and F. O. Slate, "Stress-strain response and fracture of a concrete model in biaxial loading," ACI Materials Journal, vol. 68, no. 8, pp. 590-599, 1971.

[8] T. Y. Liu, A. H. Nilson, and F. O. Slate, "Stress-strain response and fracture of a concrete in uniaxial and biaxial compression," ACI Journal Proceedings, vol. 69, no. 31, pp. 291-295, 1972.

[9] G. Prokopski and J. Halbiniak, "Interfacial transition zone in cementitious materials," Cement and Concrete Research, vol. 30, no. 4, pp. 579-583, 2000.

[10] Y. Wang, Strength and Constitutive Relationship of Recycled Aggregate Concrete under Multiaxial Stress States, Guangxi University Press, Nanning, China, 2017.

[11] S. Feng, H. Xiao, and H. Li, "Study on Comparative studies of the effect of ultrahigh-performance concrete and normal concrete as repair materials on interfacial bond properties and microstructure," Engineering Structures, vol. 222, Article ID 111222, 2020.

[12] M. Sánchez de Juan and P. Alaejos Gutiérrez, "Study on the influence of attached mortar content on the properties of recycled concrete aggregate," Construction and Building Materials, vol. 23, no. 2, pp. 872-877, 2008.

[13] J. Xiao, B. Yuan, and B. Lei, "Effect of recycled concrete coarse aggregates on service-load deflections of reinforced concrete columns," Coal Ash China, vol. 1, pp. 14-16, 2007.

[14] R. Bruno, T. Yamamoto, and Y. Yamashiki, "A study on the reduction in hydration heat and thermal strain of concrete with addition of sugarcane bagasse fiber," Materials, vol. 13, no. 13 , p. $3005,2020$.

[15] P. Stroeven, "Stereological estimation of fractal number of fracture planes in concrete," Disordered Materials and Interfaces, pp. 343-348, Materials Research Society, Pittsburgh, PA, USA, 1995.

[16] P. Yi-jiang and Y. Li-ping, Meso-Analysis Method for Recycled Concrete, Science Press, Beijing, China, 2018.

[17] S. P. Shah and G. Winter, "Inelastic behavior and fracture of concrete," ACI Materials Journal, vol. 63, no. 9, pp. 5-28, 1966.

[18] J. S. Lawler, D. T. Keane, and S. P. Shah, "Measuring three dimensional damage in concrete under compression," ACI Materials Journal, vol. 98, no. 6, pp. 465-475, 2001.

[19] B. A. Harish, N. Venkata Ramana, and K. Gnaneswar, Experimental and Analytical Studies on Recycled Coarse Aggregate Concrete, Elsevier, Amsterdam, Netherlands, 2020.

[20] J.-z. Xiao, J.-t. Du, and Q. Liu, "Numerical simulation on stress-strain curve of recycled concrete under uniaxial compression with lattice model," Journal of Building Materials, vol. 12, no. 5, pp. 511-518, 2009.

[21] M. P. Lutz, P. J. M. Monteiro, and R. W. Zimmerman, "Inhomogeneous interfacial transition zone model for the bulk modulus of mortar," Cement and Concrete Research, vol. 27, no. 7, pp. 1113-1122, 1997.

[22] X.-l. Du, Y. Wang, and D.-c. Lu, "Experimental study of biaxial compression test of cement mortar material," in Proceedings of the 2nd National Engineering Safety and Protection Academic Conference, vol. 2, pp. 236-241, Beijing, China, 2010.

[23] Z. Deng, B. Liu, B. Ye et al., "Mechanical behavior and constitutive relationship of the three types of recycled coarse aggregate concrete based on standard classification," vol. 22, no. 2, pp. 30-45, 2020.

[24] S. B. Huda and M. S. Alam, "Mechanical behavior of three generations of $100 \%$ repeated recycled coarse aggregate concrete," Construction and Building Materials, vol. 65, pp. 574-582, 2014.

[25] J. Zhou, H. He, X. Meng, and Y. Yang, "Basic mechanical properties of recycled concrete experimental study," Journal of Shenyang Jianzhu University (Natural Science), vol. 26, no. 3, pp. 464-468, 2010. 